\title{
Individual Security as an Indicator of Relationship Security among Indian Couples in an Intimate Relationship
}

\author{
Jayaseelan R*, George TS \\ Christ University, Department of Psychology, Bangalore (Karnataka), India
}

DOI: $\underline{10.36348 / \mathrm{sjhss} .2020 . \mathrm{v} 05 \mathrm{i} 06.006}$

| Received: 10.06.2020 | Accepted: 18.06.2020 | Published: 21.06.2020

*Corresponding author: Rachel Jayaseelan

\section{Abstract}

Healthy adult attachment is significant for relationship continuity and satisfaction. While security has been studied as a concept in literature, limited research exists on the experience of it in the context of relationships in India. The purpose of the research was to understand and conceptualize the experience of security in the process of tool development. A qualitative approach from a phenomenological paradigm was used to obtain rich experiences, understand it in depth and maintain the uniqueness of the data. In two separate studies, 29 participants between the ages of 18 and 32, married and those in pre-marital relationships participated either in a focus group discussion or an individual interview to share their experiences. The present paper explores how one emergent theme pertaining to individual security influences significantly relationship security. Analysis revealed how past experiences, family upbringing can influence sense of being 'valued' in the relationship and the factors they seek for in a partner to feel secure. In a rapidly westernizing culture, this information could help understand the complexities of relationships in modern India, aid in building better psychoeducational and counselling services in addition to theory building on the concept of relationship security.

Keywords: Relationship security, individual security, intimate relationship, past relationship experiences, family upbringing.

Copyright @ 2020: This is an open-access article distributed under the terms of the Creative Commons Attribution license which permits unrestricted use, distribution, and reproduction in any medium for non-commercial use (NonCommercial, or CC-BY-NC) provided the original author and source are credited.

\section{INTRODUCTION}

Divorce and broken relationships is a rising concern in today's society. A study by Dommaraju and Jones [1] showed that the number of divorced and separated people have more than doubled over the past twenty years in India. Individual security leads to healthy interpersonal relationships, triggering feelings of warmth and safeness, sets up a confidence expectancy that others will be warm, accepting, trustworthy, supportive and so on [2]. Romantic relationships are valued for being able to fulfil attachment needs and providing us reassurance of worth, social integration, and opportunity for nurturance explains Weiss [3] in his Theory of Relational provisions.

\section{Theoretical background}

Attachment theories state that individuals in a relationship are strongly driven to seek safety and security in the context of it and that secure relationships tend to last longer and associated with higher levels of satisfaction as compared to insecure relationships $[4,5]$. These theories which have been the foundation of most relationship studies states that early attachment influences the development of emotional stability, mental health and satisfying close relationships [6]. Blatz [7], who was one among the first to emphasize security as a feature in relationships, looked at it, not as a single entity but as a combination of "mature dependent security" and "mature independent security", wherein an individual depends on another for certain needs in addition to themselves [8, 9]. Research states that repeated negative experiences or patterns in the past due to caregiver/ partner rejection can lead to insecurity by causing the individual to anticipate similar outcomes in the future $[10,2,7,11,12,2]$. According to Blatz [7], the influence on adult relationships is mediated by the personality changes that take place due to disruptions of relationships with primary caregivers [13].

Majority of relationship studies derive their meaning from Western values and culture [14]. Theories and paradigms that work in one culture may not necessarily hold true in another. Mirecki \& Chou [15], in their study among immigrant families, emphasized the importance of culture and society on 
attachment. Considering the clear shortage of studies that examine relationship security in depth and factors or dimensions that constitute it from an experiential perspective, the current study takes into consideration the changing cultural context of India while understanding how individual security influences relationship security. Majority of literature in India has looked at how early attachment serves a mediating role in influencing adolescent and adult relationships. Factors such as developing a healthy personal identity, healthy views on sexuality [16], social competence [17] and even factors that influence choice of romantic partner [18] have been studied, with very little focus on the concept of relationship security itself, and its constituents in adult relationships.

It is important at this juncture, to differentiate between individual security and relationship security. Individual security is a state in which a person perceives his/her environment to be safe and free from harm and threat [19]. Individuals who are psychologically secure usually have high confidence, trust in them and significant others to meet their basic need [20]. Psychiatrists have found extensive elements of insecurity in maladjusted individuals which endanger mental health [21]. Relationship security on the other hand is interdependent and dyadic in nature.

\section{Significance and Implication}

Taking into consideration the current context of relationships in India, relationship security, which is sought after in most relationships can be synonymous with a number of factors. This paper emphasizes individual security as a constituent of relationship security and therefore, firstly, by understanding the importance of this, we can identify areas of focus in counselling. Secondly, the results will help trace back to the early influential factors such as parenting, peer relationships and even experiences in school, which can influence how secure an individual feels in an adult relationship. Awareness or insight as we know is the first stage of successful counselling. By focusing on individual factors such as self-esteem, one can indirectly influence relationship variables such as satisfaction and stability. Thirdly, data from the current research can help build Relationship Education Programs focusing on individuals having realistic expectations about their own relationships (Fincham, Stanley \& Rhodes, n.d), equipping them with coping skills and resources to function effectively. This can also help parents; teachers and peers understand their role in shaping a secure individual.

\section{METHOD Approach}

Qualitative approach, being one of the emerging and legitimate methodologies in social enquiry [22], was used to obtain rich experiences of the participants. The epistemological paradigm of phenomenology was adopted since the author wished to operationalize relationship security taking into account the lived experiences and expectations of Indian couples. Braun \& Clarke [23], outline a series of steps that help code data, tapping into the experiences of participants and the meanings they attach to them.

The definition of relationship security was first operationally constructed for the purpose of this research based on focus group discussions and individual interviews. Participants were asked to come up with phrases that define relationship security which were then given to 5 experts and revised to help construct the semi-structured interview for the studies. The definition was compared to the emergent themes to ensure that it encompassed all relevant aspects of it. The resultant definition was "A perceived sense of safety, trust and stability in the relationship where expectations are met or will be met adequately within the boundaries of the intimate relationship". The paper will look at how individual variables influence relationship security.

\section{Participants}

Individuals were selected through purposive sampling and were between the ages of 18 and 32. This sampling strategy was used to select participants who could provide rich information to study relationship security in-depth [24]. The inclusion criteria outlined that participants were either currently in a relationship, or had to have been in a relationship within the past one year. A total of 29 English speaking participants, from Urban Bangalore, a city in the South of India, were chosen to share their experiences.

\section{Procedure}

Data to help conceptualize relationship security was analysed from three phases of interaction with participants. In the first phase, nine participants were selected (five female, four male) who were individually interviewed about their experience of security in their relationship. The inclusion criteria was that individuals had to currently be in a relationship with the same partner for a minimum period of 2 months $\left[{ }^{1}\right]$, and between the ages of 18 and 25 (premarital group).

The second phase followed a similar method, and was conducted with twelve participants (six male, six female) in a focus group discussion, where they asked what security in a relationship meant, their expectations and experience of the same. The participants in this group consisted of individuals between the ages of 18 to 32 (pre-marital group), who were either currently in a relationship or recently

\footnotetext{
${ }^{1}$ Congo et al, 2000 state that less than a month is considered as minimal dating experience, whereas Meier \& Allen (2008) in their studies consider a minimum of 3 months as representative of a serious relationship.
} 
separated from their partner. Focus groups have over the years been proven to be an effective method of data collection [25]. The third phase involved individual interviews with ten individuals (six female, four male) who constituted the marital group. A demographic detail sheet was used to ensure that participants met the inclusion criteria of the study. Information was recorded following informed consent by the participants.

\section{Analysis and Validation}

Key concepts and themes were elicited from the data using an iterative step-by-step thematic analysis process, which is described to be an apt method for analysis of large qualitative data [23] and for examining the perspectives of different research participants.

The following steps as outlined by Braun \& Clarke [23] were incorporated

1. Familiarising with the data- This was achieved through active engagement with, and repeated reading of the 29 transcribed interviews and the reflexive journal.

2. Generation of initial codes- The data was organized using a data-driven approach as there was no single theory explaining the concept of relationship security. Coding was done manually as the researcher wished to engage more closely with the data set, being a relatively new area of research in India. Interesting aspects and repeated patterns were highlighted. Microsoft Excel 2008 was used for this purpose.

3. Search for Themes- The codes generated were organized into basic level themes that are outlined below. In this case, a broad (Global Theme) was 'past influenced present individual security'. Based on common meanings emphasized by participants, subthemes related to the sense of self, sense of fear and sense of control was identified.
Member check was used to increase the trustworthiness of data obtained, by asking the participants to verify accuracy or report discrepancies in the researcher's interpretation of their experiences [26].

4. Review of themes- Since the sub-themes were named in the previous stage and justified by literature, no data was discarded. Internal homogeneity (similar meaning within themes) and external heterogeneity (marked differences between themes) as emphasized by Patton [24] was adhered to. Peer debriefing was done at this stage, where a colleague trained in qualitative methodology reviewed the research process, method of analysis and results obtained. Interesting perspectives to discussing sub-themes relating to Indian culture were outlined [27].

5. Defining and Naming Themes- Themes were named once again focussing on a data- driven approach as there were a large set of participants through whose interviews, data saturation had been obtained.

A reflexive journal was maintained during the interview and analysis process which helped increase self-awareness about the researchers' belief system, values and even opinions [27] on relationships in an Indian context.

\section{RESULTS AND DISCUSSION}

Five significant themes (Figure 1) emerged from the data, and this paper discusses one theme, namely, 'Past influenced present relationship security', which outlines the different ways in which an individual functions in his/her present relationship, based on experiences with significant others in the past. In this context, the past included, upbringing, experiences with peers, parents, and even previous relationships.

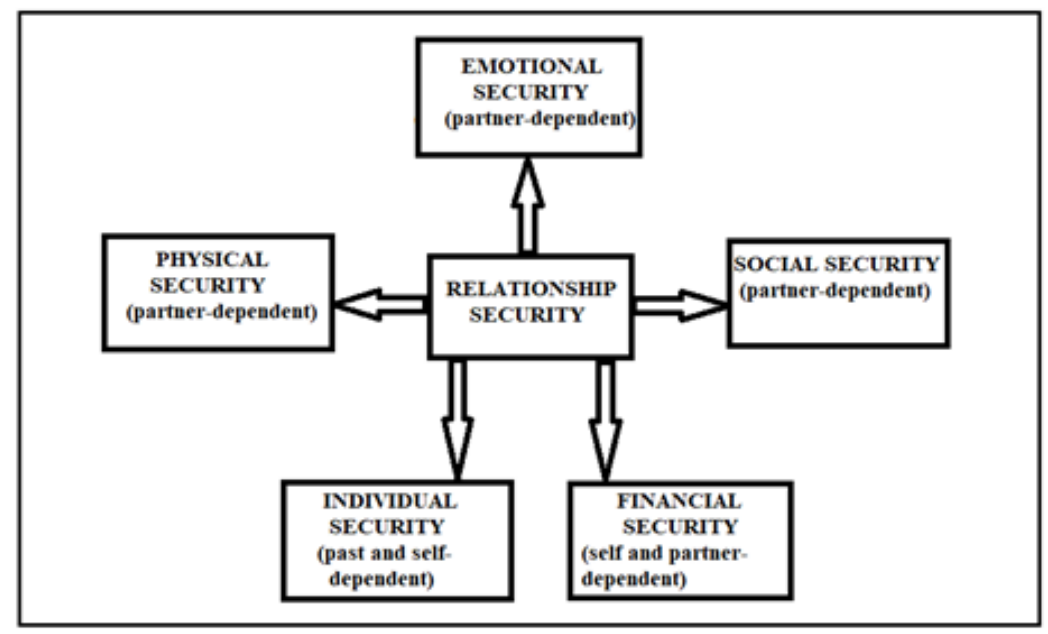

Fig-1: Thematic Network for the Relationship Security Construct 
Our critical inner voices that are created due to experiences with influential early care-givers, teachers, peers can be the root of our insecurity as adults [28]. For example, an absent parent can generate the thought "I am not loveable", or exaggerated praise, pampered upbringing can result in very high self-esteem, or a high sense of self-worth that the individual will seek confirmation/ negation for in future relationships as well. Discussed below are three sub-themes relating to the individual security theme

\section{The self and the 'self-affirming' relationship}

This sub-theme describes how individuals' selves are malleable in romantic relationships [29] which offer a platform for them to explore their insecurities.

Marigold, Holmes \& Ross [30], emphasize the self-affirming nature of romantic relationships. Evaluative judgements about oneself created by our life experiences and influenced by what others think of them, are incorporated in the self [31, 32]. Being a generation that compares, evaluates and judges ourselves with great scrutiny, the social construction of the self is significantly observed. People assume that people, themselves included, have a stable essence or core that predicts their behaviour, that that they are matters for what they do, and that what they do reflects who they are [33]. Participant CK [34], said,

It hurts me when he uses my weaknesses when we fight.. It is always, when you fall ill, who else will take care of you? ... I have accepted you even if you are like this... I mean it is true, but I already feel like as if I am not good enough and he keeps bringing this up or, this one time he mentioned about my dry skin...it was casual statement, but he knows it hurts me, so how can I feel ok in a relationship where he keeps making me feel bad about myself.

For participant CK, her personal inferiorities led her to the belief that she could never be loved again. She said, "After he left me to start dating my friend... I realized it must be because of how I looked or that I was not sexually appealing".

These statements support self-verification theories that state that individuals often seek confirmation of their previously held self-beliefs, that they have a strong desire to stabilize views about themselves [35]. Positive relationship outcomes (satisfaction and commitment) and relationship functioning is facilitated by positive self-image and self-concept [34]. People with low self-esteem, often doubt their value to their romantic partners and resist positive feedback from them [36], distancing themselves from their partner, fearing criticism or rejection [37]. One interesting trend that emerged from the data was the strong need among women to feel "valued and respected" in the relationship by their partner. The economic independence seen in women of the 21 st century appears to be influencing their sense of value in a relationship and towards themselves, their increased power, freedom of choice etc. This is contrast to the "house-wife" or domestic/ submissive role that the woman in a conservative/ collectivistic culture has been known to play.

\section{The self and the 'self-enhancing' relationship}

Physical appearance related insecurities either due to peer comparison, media standards or past relationships play an important role in relationship satisfaction. Participants look towards their partner to make them feel beautiful.

Participant SH (personal communication, February 10, 2014), said, "He is very appreciative... about my ability also he keeps going on and on about how attractive he finds me and I guess in that way he kind of reinforces or eliminates any insecurity that I have". Most of them felt that with their partner, they could be their real self and hence explore, come to terms with, and even work on their insecurities. According to Firestone [28] it is about not losing oneself in the process of adjusting to a relationship and accommodating to a new partner, but of becoming a better self. Participants who were independently secure preferred partners who were secure and with whom they could relate to on a more mature level. It was seen that often in the attempt to seek clarification for or negate self-beliefs in the context of the relationship, individuals experience a change in the self and their attitudes towards their self.

\section{Sense of fear}

Relationships, in particular, can stir up past hurts and experiences by awakening long buried insecurities, bringing up emotions we don't expect. In a study done among divorced couples in Netherlands in 2000, 'fear of intimacy' was indicated as one of the most common reasons [28, 9] for the decision. Early experiences with closeness are important in the creation of healthy internal representations about intimacy. Being close to someone else can trigger certain emotions and critical inner voices and listening to this, can cause us to feel desperate toward our partner or pull back when things start to get serious. It can exaggerate feelings of jealousy or possessiveness or leave us feeling rejected and unworthy. This pattern is more commonly seen among individuals with an insecure attachment style. When vulnerable behaviour in a romantic relationship is punished, intimacy might be feared leading to less satisfactory relationships [38]. Ruvola, Fabin \& Ruvolo [39] showed that people experiencing a break-up became less willing to trust others, less comfortable being close to others, and less secure about initiating future relationships. As adults, insecure individuals feel that others are reluctant to get as close as they would like, and they are preoccupied 
with the possibility of rejection [12]. This is a strategy to avoid hurt and any changes to the 'sense of self'.

'Fear of abandonment' also strongly fuels insecurity and is considered to be one of the underlying dimensions of anxious attachment patterns [1,20]. The fear of losing love, or of being rejected or abandoned, is a central issue for many clients that can cause hypervigilance [39] excessive questioning and constant checking behaviours [40] in relationships. Rejections from early caregivers feed insecure working models. The child believes that the world is unpredictable, even hostile [8] and a change in the sense of self [29] is experienced when a romantic relationship ends, affirming their belief about the same. Described as rejection sensitivity, this in turn feeds their anxiety to expect, readily perceive, and overreact to real or imagined rejection.

A third fear that emerged is the 'fear of engulfment', where participants felt that they might lose themselves in the relationship if they spend too much time on it and not get time for themselves. Most individuals who were well educated, working and independent emphasized on the need for 'privacy' and 'space'.

\section{Sense of control}

The desire to feel secure can sometimes cause people to take actions that would reduce the actual damage to their sense of self. According to Blatz [7], this can occur if a person reasons a situation to be sufficiently familiar or if a learned pattern of behaviour gives him/ her reassurance to deal with the any threat to the sense of stability or the confidence that some factor will prevent him/her from suffering unacceptable consequences. Participant BG (personal communication, April, 2018) said,

She doesn't like it when I meet my friends, even if they are guys, its like I have to spend all my free time with her, she wants to control my social life completely, know who I am talking to, or who I am messaging, to the point that she was all I had and it was that phase that I went into depression... and when we broke up, I told her she has to get over her insecurities or she will not have a proper relationship at all.

Relationship satisfaction according to Spielman, McDonald \& Tackett [41] involved active avoidance or even planned avoidance of perceived social threats. This may be expecting the partner to give up his/her party life, monitoring social networking sites or even cutting away friendships with same sex individuals perceived as a threat. Individual insecurities can reflect personal inferiorities and fears.

Participants also shared the precautionary behaviours, emotions and attitudes they engaged in to stabilize the relationship. Safety and relationship monitoring behaviours indicated a need to control aspects of the relationship. Jealousy often related to insecurity equips the individual to protect their relationship if they deem it worthy [42].

Participant EN (personal communication, March 17, 2014) said, "So I keep checking his Facebook...See he can chat with girls and all... but I want to see them... so we keep checking each other's accounts..." Lindner [43] in a study on face-book stalking reported it as a sign of jealousy, insecurity and decreased relationship satisfaction. She further adds that occasionally she deletes messages of girls from his phone before he sees it thus preventing contact with a perceived threat. Increased alertness through monitoring and warding off potential rivals are behaviours seen associated with jealousy [42].

\section{SUMMARY}

In the context of relationships in India, where the partner and the family have been known to play an influential role, security is also determined by the individual's sense of self which is influenced by his/her life experiences tracing all the way back to experiences with early caregiver. In this study, it was observed that participants often use the relationship as a platform to work on their developed insecurities either seeking to affirm or enhance their sense of self. Individuals have a natural tendency to crave social rewards in relationships and report more satisfaction if there is a "feel good" factor in the same. While one cannot change the past, in addition to working on relationship dependent variables, it is also possible and more realistic to focus on methods to increase independent variables such as self-esteem. Partner appreciation for example is important to those who feel the need to dispel past influenced insecurities about the self [41]. Counselors and psychologists can help individuals have a positive view of them, help them set anchors in their independent achievements as well. Those with higher emotional intelligence for example, found their partner to be less critical and more supportive of them [44]. Working on emotional intelligence therefore can help create more resilience or help a person better deal with variables that threaten relationship security in a more mature manner. To help improve relationship security therefore, even in the absence of the partner or constraints in working with relationship variables, one can focus on individual variables such as goal orientation [44]. While emphasising on parenting techniques to build a healthier inner critic, increased awareness about mature conflict resolution strategies, even building healthy relationship in schools, preventing bullying etc, that can damage independent self-esteem, can help strengthen the individual in the relationship. Further studies can focus on identifying independent factors that can influence sense of self and methods to enhance the same. Cross cultural studies can compare the nature of these variables between individualistic and collectivistic societies taking into 
account differences in parenting styles, schooling systems and nature of premarital and marital relationships.

\section{REFERENCES}

1. Dommaraju, P., \& Jones, G. (2011). Divorce trends in Asia. Asian Journal of Social Science, 39(6), 725-750.

2. Baldwin, M.W. (2007). On priming security and insecurity. Psychological Inquiry.

3. Weiss, R. (1974). The provisions of social relationships. Rubin, Z., (Ed.), Englewood Cliffs: Prentice Hall.

4. Pearce,R (2009). Attachment theory predicts the formation of romantic relationships. Griffith University Undergraduate Student Psychology Journal, 1 ,

5. Candel, O., \& Turliuc, M. N. (2019). Insecure attachment and relationship satisfaction: A metaanalysis of actor and partner associations. Personality and Individual Differences.147. 190199.

6. Sandberg, J. G., Busby, D.M., Johnson, S.M.\& Yoshida, K. (2012). The brief accessibility, responsiveness, and engagement (BARE) scale. Family Process. 51(4), 512. Retrieved from https://doi.org/10.1111/j.1545-5300.2012.01422.x

7. Rosmalen, L., Van der Horst, F., \& Van der Veer, R. (2016). From secure dependency to attachment: Mary Ainsworth's Integration of Blatz's Security Theory into Bowlby's Attachment Theory. History of Psychology. 19. 22-39.

8. Ainsworth, M. S. (1979). Infant-mother attachment. American Psychologist, 34(10), 932937. http://dx.doi.org/10.1037/0003066X.34.10.932

9. Vangelisti, A.L., \& Beck, G. (2007). Intimacy and Fear of Intimacy. In: L'Abate L. (eds) LowCost Approaches to Promote Physical and Mental Health. Springer, New York, NY

10. Baldwin, M.W., \& Meunier, J. (1999). The cued activation of attachment relational schemas. Social Cognition and Relationships: 17, 209227.https://doi.org/10.1521/s oco.1999.17.2.209

11. Read, M. A., Whitley, M. Z., Williams, A. J., \& Collins, T. (1994). NF-kappa B and I kappa B alpha: an inducible regulatory system in endothelial activation. The Journal of experimental medicine, 179(2), 503-512.

12. Hazan, C., \& Shaver, P. (1987). Romantic love conceptualized as an attachment process. Journal of Personality and Social Psychology, 52(3), 511524. http://dx.doi.org/10.1037/0022-3514.52.3.511

13. Volpe, R. (2010). The secure child. Timeless lessons in parenting and childhood education. Toronto:Universal Toronto Press. Retreived from : http://www.infoagepub.com/index.php?id=9\&p=p4 b2021ed5124e

14. Rothbaum, F., Weisz, J., Pott, M., Miyake, K., \& Morelli, G. (2000). Attachment and culture:
Security in the United States and Japan. American Psychologist, 55(10), 1093-1104.

15. Mirecki, R.M., \& Chou, J.L. (2013). A multicultural application of attachment theory with immigrant families: Contextual and developmental adaptations. Contemporary Family Therapy, 35(3). 508-515.

16. Ganth, D.B., \& Kathiravan, S. (2017). Psychosocial determinants of romantic inclination among Indian youth. An International Journal on Personal Relationships. 11(1): 22-39.

17. Kumar, D.M.S., \& Raj, S.J.M. (2016). The impact of attachment styles on social competence of adolescent students. Artha Journal of Social Sciences, 15(1), 1-15

18. Gerdvilyte, A., \& Abhyankar, S.C. (2010). The compatibility of ideal and real romantic partner characteristics, attachment to partner and relationship satisfaction among Indian women. Psychological Studies.55, 188-194.

19. Maslow, A. H., Hirsh, E., Stein, M., \& Honigmann, I. (1945). A clinically derived test for measuring psychological security-insecurity. Journal of General Psychology, 33, 21-41.

20. Calvo, V., \& Bianco, F. (2015). Influence of adult attachment insecurities on parenting self-esteem: the mediating role of dyadic adjustment. Frontiers in psychology, 6, 1461.

21. Cameron, W. B., \& McCormick, T.C. (1954). Concepts of security and insecurity. American Journal of Sociology, 59(6). 556-564. https://doi.org/10.1086/221442

22. Gale. (1993). A field guide to qualitative inquiry and its clinical relevance. Contemporary Family Therapy, 15(1), 73-91.

23. Braun, V., \& Clarke, V. (2006). Using thematic analysis in psychology. Qualitative Research in Psychology, 3(2), 77-101.

24. Patton, M.Q. (2002). Qualitative Evaluation and Research Methods (2nd Ed.).

25. Fielden, A., Sillence, E., \&Little, L. (2011). Children's understandings of obesity, a thematic analysis. International Journal of Qualitative Studies on Health and Well-Being, 6(3). 71707183.

26. Cresswell, J.W., \& Miller, D.L. (2000). Determining validity in qualitative inquiry. $A$ Theory into Practice, 39(3). 124-130. https://doi.org/10.1207/s15430421tip3903_2

27. Lincoln, Y. S., \& Guba, E. G. (1985). Naturalistic inquiry. Newbury Park, CA: Sage.

28. Firestone, L. (2011). Conquer your critical inner voice. Retrieved from https://www.psychalive.org/wpcontent/uploads/2011/11/conquer-your-innervoice.pdf

29. Slotter. (2010). Who am I without you? The influence of romantic breakup on the selfconcept. Personality and Social Psychology Bulletin, 36 (2): 147 
30. Marigold D.C, Holmes J.G., \& Ross,M. (2007). More than words: reframing compliments from romantic partners fosters security in low selfesteem individuals. Journal of Personality and Social Psychology. 92(2),232-48.

31. Felson, D. T., Anderson, J. J., Hannan, M. T., Milton, R. C., Wilson, P. W., \& Kiel, D. P. (1989). Impaired vision and hip fracture: The Framingham Study. Journal of the American Geriatrics Society, 37(6), 495-500.

32. Wallace, H. M., \& Tice, D. M. (2012). Reflected appraisal through a 21st-century looking glass. M. R. Leary \& J. P. Tangney (Eds.), Handbook of self and identity (2nd ed., 124-140). New York, NY: Guilford.

33. Oyserman, D., Lewis Jr, N.A.,Yan, V.X. Fisher, S., O'Donnell, C., \& Horowitz,E. (2017) An Identity-Based Motivation Framework for SelfRegulation, Psychological Inquiry, 28:2-3, 139147.

34. Mattingly, B.A., McIntyre, K.P., Knee, C.R., \& Loving T.J. (2018). Implicit theories of relationships and self-expansion: Implications for relationship functioning. Journal of Social and Personal Relationships, 36(6), 1579-1599.

35. Kwang, T., \& Swann Jr, W. B. (2010). Do people embrace praise even when they feel unworthy? A review of critical tests of self-enhancement versus self-verification. Personality and social psychology review, 14(3), 263-280.

36. Lemay, E. P., \& Clark, M. S. (2008). "You're Just Saying That." Contingencies of Self-Worth, Suspicion, and Authenticity in the Interpersonal Affirmation Process. Journal of experimental social psychology, 44(5), 1376-1382.

37. Murray, S., Holmes, J., Macdonald, G., \& Ellsworth, C.P. (1999). Through a looking glass darkly? When self-doubts turn into relationship insecurities. Journal of Personality and Social Psychology, 75. 1459-80.

38. Cordova, J. V., \& Scott, R. L. (2001). Intimacy: A behavioral interpretation. The Behavior analyst, 24(1), 75-86.

39. Faber, U. (2010). The role of anxious relationship beliefs in relationship satisfaction and relational maintenance behaviour. (Published Dissertation). Retrieved from file://C:/Users/Rachel/Downloads/faber3054039\% 20(1).pdf

40. Jayaseelan, R. (2015). Experience of security among emerging adults in a romantic relationship. (Unpublished dissertation). Christ University. Bangalore

41. Spielman, S.S., MacDonald, G., \& Tackett, J.L. (2011). Social threat, social reward, and regulation of investment in romantic relationships. Personal Relationships, 19. 601-622. doi: 10.1111/j.14756811.2011.01377.x

42. Adams, S. (2012). Jealousy in romantic relationships, self-esteem and ego defenses. (Other Degree thesis) Victoria University, Melbourne.

43. Lindner, K,A. (2008). The effects of facebook "Stalking" on romantic partners' satisfaction, jealousy, and insecurity. (Master's Disssertation). Retrieved from https://indigo.uic.edu/bitstream/handle/10027/9569 /Lindner_Katherine.pdf?sequence $=1$

44. Amitay, O. A., \& Mongrain, M. (2007). From emotional intelligence to intelligent choice of partner. The Journal of Social Psychology, 147(4), 325-343. http://dx.doi.org/10.3200/S 